\title{
NATIONAL INSTITUTES OF HEALTH
}

\section{Enacted Appropriations for FY 2008-FY 2010}

(Dollars in Thousands)

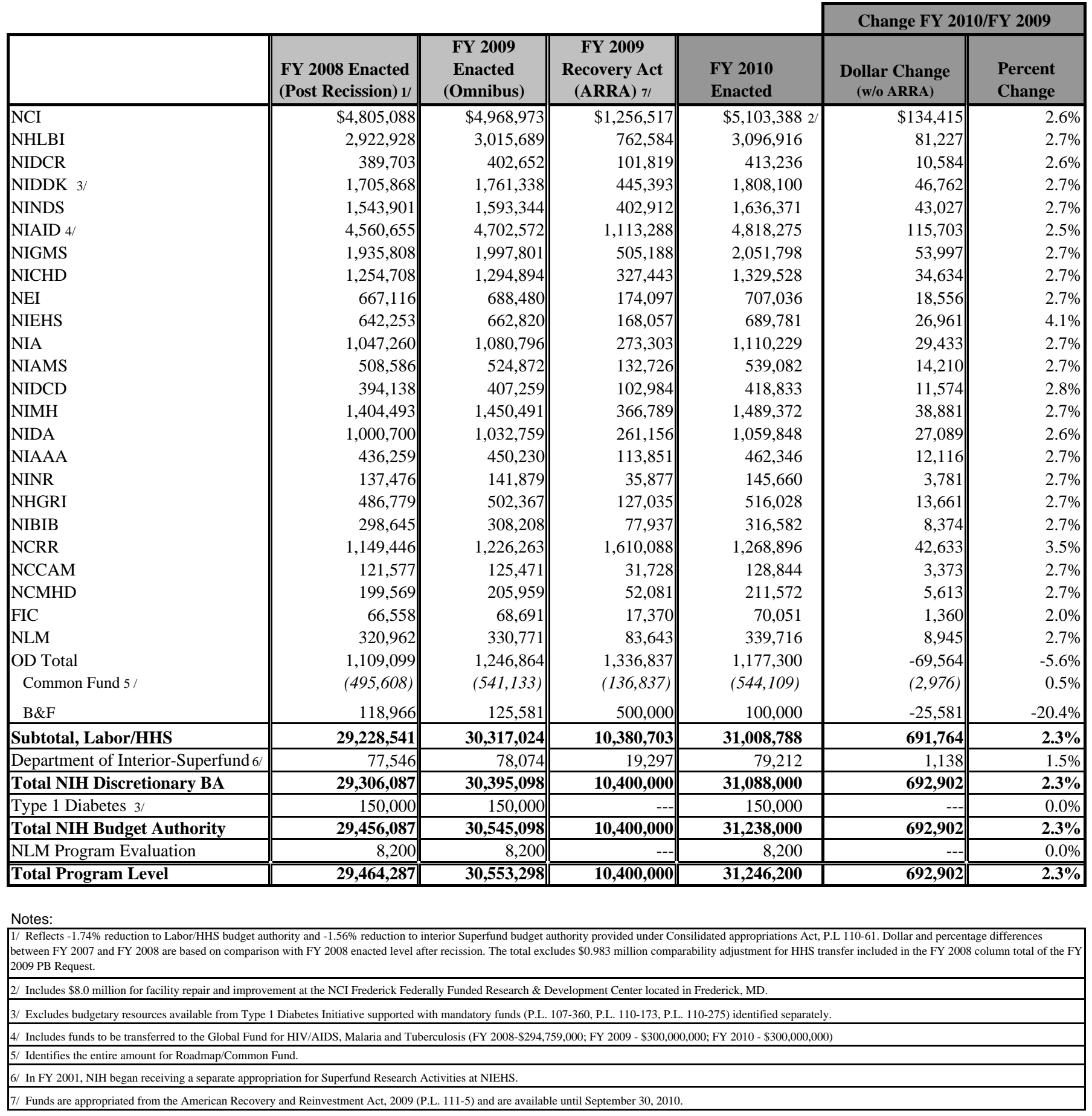

